\title{
Indexação verbo-sujeito nas línguas Tukáno: categorização dos referentes nominais e sua codificação nos verbos
}

\author{
Subject-Verb indexing strategies in Tukanoan languages: \\ the codification and categorization of nominal referents on verbs \\ Thiago Costa Chacon
}

\begin{abstract}
Resumo
Este trabalho discute os sistemas de indexação de sujeitos nos verbos em línguas da família Tukáno. Problematizamos como se dão as relações entre as categorias de CLASSIFICAÇão NOMINAL, PESSOA e NÚMERO nestes sistemas, além de analisar o estatuto dos morfemas indexadores na sintaxe de cada língua como marcas de CONCORDÂNCIA, CORREFERÊNCIA e/ ou ARGUMENTOS VERBAIS. Línguas da família Tukáno possuem uma rica morfologia verbal, que também marca diversas categorias modais, evidenciais, temporais, aspectuais, além de tipos de orações (declarativas, interrogativas e imperativas). Oferecemos uma análise com atenção à tipologia dos sistemas de classificação nominal, pessoa e número, além de discussões sobre questões pragmático-funcionais que estão subjacentes aos sistemas analisados. Palavras-chave: Classificação nominal. Número. Pessoa. Indexação. Língua Tukáno.
\end{abstract}

\section{Abstract}

This paper is about the systems of indexation of subject arguments on verbs in languages from the Tukanoan Family. It is concerned with how the categories of nominal classification, person and number interact in these systems, as well as with the syntactic status of indexing morphemes as markers of agreement, correference and/or verb arguments. Tukanoan lanmguages have a rich verb morphology, which also code several modal, evidential, temporal and aspectual categories, as well as clause types (declaratives, interrogatives and imperatives). The analyses focus on the typology of nominal classification, person and number, and provides discussion of relevant functional-pragmatic issues.

Keywords: Nominal Classification. Number. Person. Indexation. Tukanoan languages.

\section{Introdução}

Este trabalho discute os sistemas de indexação de sujeitos verbais em línguas da família Tukáno. Línguas dessa família possuem uma rica morfologia verbal, que além de marcar pessoa, número e classificação nominal, também marca diversas categorias modais, evidenciais, temporais, aspectuais, além de tipos de orações (declarativas, interrogativas e imperativas). Cada língua possui diversos paradigmas de afixos verbais e construções perifrásticas, onde muitas vezes categorias de pessoa, número e classificação nominal se encontram fundidas com outras categorias flexionais verbais. Devido à essa complexidade, 
limitamos o escopo desse trabalho para os paradigmas de flexão verbal de orações declarativas, com evidencialidade visual ou de primeira-mão, modo realis e em construções não-perifrásticas.

Problematizamos como se dão as relações entre as categorias de CLASSIFICAÇÃO NOMINAL, PESSOA e NÚMERO nestes sistemas, e o estatuto dos morfemas indexadores na sintaxe como marcas de concordância, correferência e/ou argumentos verbais. Oferecemos uma análise com atenção à tipologia dos sistemas de classificação nominal, pessoa e número, além de discussões sobre motivações pragmático-funcionais por trás da lógica desses sistemas ${ }^{1}$.

Chacon (2014) consolida a proposta de Mason (1950) ao classificar as línguas Tukáno com base na distinção tradicional em dois ramos da família: Tukáno Oriental (TOr) e Tukáno Ocidental (TOc). Ao todo são mais de 20 línguas Tukáno correntemente faladas no Noroeste e Oeste da Amazônia. Veja a classificação das principais línguas da família abaixo (ver Chacon 2014)2:

\section{Figura 1}

Tukáno Oriental (TOr)

\begin{tabular}{|c|c|c|c|}
\hline TOr do Sul & TOr do Oeste & \multicolumn{2}{|l|}{ TOr do Leste } \\
\hline \multirow{2}{*}{$\begin{array}{l}\text { TAN Tanimuka } \\
\text { RET Retuarã } \\
\text { YAH Yahuna }\end{array}$} & \multirow{2}{*}{$\begin{array}{l}\text { MAK Makuna } \\
\text { BAS Barasano } \\
\text { KUB Kubeo } \\
\text { DES Desano } \\
\text { SIR Siriano } \\
\text { YUP Yupua }\end{array}$} & Ramo-I & Ramo-II \\
\hline & & $\begin{array}{l}\text { TuK Tukano } \\
\text { BAR Bará } \\
\text { TAT Tatuyo }\end{array}$ & $\begin{array}{l}\text { PIS Pisamira } \\
\text { KAR Karapanã } \\
\text { YUR Yuruti } \\
\text { TUY Tuyuka } \\
\text { PIR Piratapuya } \\
\text { WAN Wanano }\end{array}$ \\
\hline
\end{tabular}

${ }^{1}$ Para classificação nominal ver: Aikhenvald (2000), Senft (2000), Grinevald e Seifart (2004), Gomez-Imbert (2007). Swirieska (2004), Corbett (2000, 2006), Haspelmath (2013) e Croft (2013) trazem diferentes perspectivas sobre a discussão do papel de formas pessoais, marcadores de número e gênero/classes nominais, bem como seu estatuto gramatical com correferenciadores, indexadores, anafóricos e argumentos.

${ }^{2}$ As generalizações proposta neste trabalho são potencialmente válidas para todas as línguas da família. No entanto, analisamos apenas as seguintes línguas que possuem uma melhor documentação gramatical e são representativas da diversidade interna da família: línguas TOc - Siona (Wheeler 1987; Bruil 2013), Koreguahe (Cook e Criswell 1993) e Maihïki (ou Orehon, Skilton 2013); línguas TOr - Retuarã (Storm 1992), Kubeo (Morse e Maxwell 1999; Chacon 2012), Desano (Miller 1999, Silva 2012) Wanano (Stenzel 2013), Tatuyo, Barasano (Gomez-Imbert 2000), Tukáno (Ramirez 1997, Chacon 2007)e Tuyuka (Barnes 1984, Malone 1988). 
Tukáno Ocidental (TOc)

\begin{tabular}{|l|l|l|}
\hline KUE Kueretu & TOc do Sul & TOc do Norte \\
\cline { 2 - 3 } & MAI Maihiki & KOR Koreguahe \\
& & $\begin{array}{l}\text { SEK Sekoya } \\
\text { SIO Siona }\end{array}$ \\
\hline
\end{tabular}

Na seção 1.1 a seguir, definimos os conceitos centrais e o foco de nosso estudo. Na seção 2, introduzimos brevemente as categorias dos sistemas de classificação nominal, pessoa e número para a classe dos nomes. Na seção 3, oferecemos uma tipologia dos sistemas de indexação verbo-sujeito nas línguas da família. Na seção 4, apresentamos uma análise que evidencia as hierarquias funcionais dos diferentes sistemas e os explica com base em motivações pragmáticas e funcionais. A seção 5 traça a conclusão deste estudo.

\subsection{Concordância e indexação verbal nas línguas Tukáno}

Em todas as línguas da família Tukáno, o único argumento de verbos intransitivos (S) ou o argumento mais prototipicamente agente de um verbo transitivo (A) - i.e. os sujeitos em um sistema de alinhamento tipicamente acusativo-nominativo $^{3}$ - são indexados nos verbos por um conjunto de categorias que abrangem PESSOA, NÚMERO e CLASSIFICAÇãO NOMINAL (cf. Seção 2). Os exemplos abaixo da língua Kubeo ilustram a concordância de $\mathrm{A}$ e $\mathrm{S}$ com verbos:

(1a) hi-páko eda-biko
meu-mãe chegar-3.FEM ${ }^{4}$
'minha mãe chegou'

${ }^{3}$ Línguas como o Retuarã (Strom 1992) e Tatuyo (Gomez-Imbert 1982, 2004) também possuem marcas prefixais para os argumentos em função de objetos, o que não afeta $o$ alinhamento nominativo-acusativo.

${ }^{4}$ Lista de abreviaturas usadas neste trabalho em ordem alfabética (tentamos utilizer as categorias dos autores citados sempre que possível): 3 .MSC ' $3^{\mathrm{a}}$ pessoa singular masculino'; 1/2/3IN ' $1^{\text {a }}$, $2^{\text {a }}$ pessoas animado, ou $3^{\text {a }}$ pessoa inanimado'; 3AN.PL 'terceiro animado plural'; ADD 'aditivo'; ANAF 'anafórico'; CL.AN.COL 'classificador animado coletivo'; CL.RIO 'classificador rio'; COP.1/2/3IN/3PL 'cópula de $1^{\text {a }}, 2^{\text {a }}$ pessoas animado, ou $3^{\text {a }}$ pessoa inanimado'; COP.3AN.SG 'cópula $3^{\text {a }}$ pessoa animado singular'; DEF 'definido'; EP 'epentético'; EST 'estativo'; FEM 'feminino'; FUT 'futuro'; INCL 'Inclusivo'; INT 'intensificador'; LD 'limitador espacial'; LOC 'locativo'; LOC.ESP 'locativo específico'; NEG 'negativo'; NMZ.IN 'nominalizador inanimado'; NMZ.MSC 'nominalizador masculino'; NOM 'nominalizador'; NOM.SG 'nominativo singular'; OBJ 'objeto'; PER 'perfeito'; PL 'plural'; POT 'potencial'; PRCS 'precisamente'; PRES.3SG.FEMININO 'presente $3^{\text {a }}$ pessoa singular feminino'; PRES.3SG.NÃO.FEMININO 'presente $3^{\mathrm{a}}$ pessoa singular não feminino'; PRES. GENÉRICO 'presente genérico'; PROG 'progressivo'; SG 'singular'; SUS.PL 'substantivador 
$\begin{array}{cll}\text { (1b) hi-páki } & \text { ũkũiye } & \text { ũkũ-mi } \\ \text { meu-pai } & \text { caxiri } & \text { beber-3.MSC }\end{array}$

'meu pai tomou caxiri'

(1c) mahe $=$ wi eda-i-ma

$\operatorname{nosso}(\mathrm{INCL})=\mathrm{CL} \cdot \mathrm{AN} \cdot \mathrm{COL} \quad$ chegar-EST-3AN.PL

'nossos parentes estão chegando'

Nessa relação de CONCORDÂNCIA, os argumentos CONTROLADORES A e S, identificados pelos os traços semântico-gramaticais como animados, singulares, masculinos/femininos e terceira pessoa, CONTROLAM a concordância com os ALVOS - os verbos - a partir desses mesmos traços (cf. Corbett 2006).

Na maioria das línguas Tukáno, os sufixos que marcam concordância verbo-sujeito são obrigatórios, enquanto a expressão dos argumentos na oração por nomes e pronomes não é obrigatória. Isso faz com que analisemos estes sufixos não como marcas de CONCORDÂNCIA CANÔNICA (Corbett 2006), mas como marcas mais gerais de CORREFERÊNCIA verbo-sujeito (cf. Haspelmath 2013:9 para o termo de cross-indexes).

Línguas excepcionais na família são o Retuarã (Strom 1992), Tatuyo e Barasano (Gomez-Imbert 1982, 2000, 2004), em que pronomes prefixais possuem um estatuto gramatical diferente, sendo alguns obrigatórios. Seu estatuto entre formas de correferência, marcas de concordância ou argumentos é problemático (cf. seções 3.8 e 3.6 respectivamente). Dessa maneira, para abranger tanto as línguas excepcionais, quanto as demais, usamos o termo mais amplo de INDEXADORES para nos referir a todas formas que estão presentes nos verbos em referência a um de seus argumentos (cf. Haspelmath 2013).

Alguns verbos, no entanto, não apresentam esse sistema de indexação verbo-sujeito simplesmente por não terem sujeitos. Isso ocorre com verbos sem argumentos (como em [2a] abaixo) e com verbos que tratam $\mathrm{S}$ como um argumento oblíquo (como em [2b]). Os exemplos em (2) abaixo são novamente da língua Kubeo:

(2a) hawe oka-wi

já chover-1/2/3IN

'já choveu'

(2b) yi-re çiki-no-um

eu-N.NOM soluçar-NMZ.IN-COP.1/2/3IN/3PL

'Eu tenho soluço (lit. me está soluçando)'

plural'; vBLZ 'verbalizador'; vIS.IMPERF.1 'visual imperfectivo 1a pessoa'; vIS.IMPERF.2/3 'visual imperfectivo $2^{\mathrm{a}}$ e $3^{\mathrm{a}}$ pessoa'; VIS.PERF. 1 'visual perfectivo $1^{\mathrm{a}}$ pessoa'. 
Um fato que merece destaque nas línguas Tukáno é que os sufixos que ocorrem nos tipos de predicados em (2) são também usados para indexar certos tipos de sujeitos. Por exemplo, em Kubeo os sujeitos que são da $1^{\mathrm{a}}$ e $2^{\mathrm{a}}$ pessoa animada e $3^{\text {a }}$ pessoa inanimado são indexados nos verbos dos exemplos em (3) com o mesmo sufixo encontrado em (2a) - um fato raro tipologicamente ao agrupar tipos de sujeitos tão díspares:
(3a) hawe ã-wi yi
já comer-1/2/3IN eu
'já comi'
(3b) $\mathrm{mi} \quad$ ke a-wi-ra
você assim dizer-1/2/3IN-PRCS
'você disse precisamente isso'
(3c) kawabi ti-i-na
hápura te-wi
hoa-i
galho cair-EST-LOC.ESP escutar fazer-1/2/3IN longe-LOC
'ouviu-se um galho cair lá longe'

Como podemos ver, com base nas orações em (1) esperaríamos concordância do verbo com os sujeitos, mas o que encontramos é um sufixo usado tanto em orações sem sujeitos, como em (2), quanto com sujeitos, como em (3). Vamos nos referir a esses tipos de marcadores de INDEXADORES GENÉRICOS.

Indexadores genéricos formam um padrão bem difundido nas línguas Tukáno, apesar de haver uma grande variação nos traços de pessoa, número e classificação nominal que eles atualizam. Nossa investigação dá especial ênfase às diferentes categorias que os indexadores genéricos podem codificar e sua função em cada um dos paradigmas a serem analisados (seções 3 e 4). Como mostraremos, os indexadores genéricos são as formas não-marcadas em um paradigma. O que é "não-marcado" é por nós tomado como algo puramente interno aos paradigmas, ou seja: são as formas contrastivas de um paradigma com uso mais geral, abrangendo um número maior de categorias e criando agrupamentos de categorias tipológica e semanticamente aparentemente não motivadas 5 .

Ao investigar os paradigmas, estaremos atentos à correlação entre o que são elementos marcados e não marcados nesses paradigmas e o estatuto tipológico das categorias que eles codificam com relação à noção de marcado e não marcado

\footnotetext{
${ }^{5}$ Por exemplo, a $1^{\text {a }}$ pessoa singular do Português é tomado como uma forma marcada (com formas exclusivas em - $o$ no presente), enquanto as formas de $3^{\text {a }}$ pessoa de variedades nãopadrão do Português são não-marcadas, pois são "extensíveis" às demais pessoas e números (e.g "você comprou", "ele comprou", "nós comprou", etc.) e a orações sem-sujeitos (e.g. "choveu").
} 
sob um ponto de vista tipológico, explicitado nas reconhecidas hierarquias de animacidade, concordância, pessoa e número, além de considerações de ordem pragmático-funcional.

\section{Categorias de classificação nominal, pessoa e número}

Nessa seção, introduzimos o leitor brevemente ao sistema de categorização de referentes nominais nas línguas Tukáno. Apresentaremos uma síntese mais do que uma análise propriamente, uma vez que nosso foco é no sistema de indexação verbal.

\section{Classificação nominal}

Nas línguas da família Tukáno, existe um rico sistema de classificação nominal que relaciona as seguintes categorias ${ }^{6}$ (cf. Gomez-Imbert 1982, 2011, Wheeler 1987, Cook e Criswell1993, Ramirez 1997, Stenzel 2013, Silva 2012, Chacon 2007, 2012).

Animacidade: cria uma divisão dos nomes em duas classes ANIMADO e INANIMADO. Essas duas classes são sub-categorizadas por diversas categorias descritas abaixo. A classe de animados inclui pessoas, animais, corpos celestes, espíritos e certas doenças. A classe dos inanimados inclui plantas e todo o resto de coisas não classificadas como animados.

Gênero: com subcategorização do sexo dos nomes animados em FEMININO e NÃO-FEMININO. Apesar de haver nomes como termos de parentesco que parecem ser flexionados como masculino e feminino (e.g. paki 'pai' pako 'mãe' em Tukáno), em geral percebemos que a categoria de feminino é marcada com relação à categoria de masculino (i.e. não-feminino). Por exemplo, jai 'onça' e jai-o 'onça fêmea' em Tatuyo (Gomez-Imbert 2007:412) evidencia que o feminino requer um marcador específico. Em Kubeo, os poucos nomes cuja forma de citação é dada no feminino, como káyu-ko 'galinha', indicam o sexo masculino pela base nominal sem afixação, káyu 'galo'. Quando o gênero de um nome animado é indeterminado, a correferência com modificadores e verbos se dá com os morfemas de não-feminino. Veja o exemplo (4) abaixo:
(4) ake
ãyu-gi
nî̂-mi
macaco ser.bonito-NMZ.MSC ser-3MSC
‘o macaco é bonito' (Ramirez 1997:200)

\footnotetext{
${ }^{6}$ As variações na maneira de classificar os referentes nominais entre as diferentes línguas Tukáno não é uma questão de princípios, mas, sim, de detalhes, sendo as categorias propostas abaixo válidas para a família como um todo.
} 
Humanidade: com a subcategorização da classe de animados em humanos e não-humanos. Na morfologia nominal, apenas a língua Retuarã (Strom 1992) possui uma categorização explícita de referentes humanos e nãohumanos. Os referentes não-humanos são flexionados por um sufixo neutro, também usado para referentes inanimados (e.g. waวi-a 'peixe [animado nãohumano]' e wiวi-a 'casa [inanimado]'). Os referentes humanos, por outro lado, são subcategorizados por sufixos de gênero. Nas demais línguas Tukáno, a distinção é mais sutil pois não-humanos não são tratados como inanimados ou por uma classe "neutra". Por exemplo, na língua Wanano (Stenzel 2013:102), os nomes humanos são obrigatoriamente marcados por morfemas de gênero, enquanto os não-humanos não o são.

Número e genericidade: referentes animados são subcategorizados em singulares e plurais; alguns são inerentemente plurais e devem ser singularizados (e.g. wa'i 'peixe' e utia 'cabas' em Tukáno), outros são inerentemente singulares e devem ser pluralizados (e.g. imi 'homem'). Algumas evidências nos levam a crer que "plural" em línguas Tukáno torna os nomes sem um referente específico, i.e. "plural" e "genérico" tendem a ser semanticamente equivalentes. Os referentes inanimados são tradicionalmente subcategorizados como "contáveis" e "incontáveis" nas línguas TOr. Assim, a distinção entre plural e singular somente ocorre para os nomes "contáveis". É possível que boa parte dos nomes classificados como "incontáveis" sejam de fato termos genéricos, e a pluralização de termos contáveis os torna, potencialmente, termos genéricos. Essas considerações nos levam a crer que "singular/individualizado" é a categoria marcada, enquanto "plural/genérico" é a categoria não marcada. Nas seções 3 e 4 exploraremos essas questões para o sistema de indexação verbo-sujeito.

Classificadores: com a subcategorização dos referentes inanimados "contáveis" e apenas alguns dos referentes nominais animados não-humanos em categorias de FORMA, ORDENAMENTO e FUNÇÃO. Essas categorias são expressas por morfemas (de seis a pouco menos de trinta, dependendo da língua) que se encontram num estatuto gramatical entre o polo lexical e funcional (Grinevald 2000), que funcionam como morfemas flexionais, derivacionais e/ou correferenciais (cf. Ramirez 1997, Gomez-Imbert 2007, Stenzel 2013, Chacon 2012).

As categorias descritas acima fazem parte de um rico sistema de classificação nominal evidenciado por diversos fatores morfossintáticos, desde a classificação de raízes lexicais, à formação da palavra gramatical (flexão inerente e derivação), concordância entre um núcleo nominal e os modificadores do sintagma nominal (SN) e a indexação verbo-sujeito. 
As categorias que operam classificação dos referentes nominais de sujeitos são uma redução das demais categorias presentes na classificação dos referentes dos nomes. As línguas e os paradigmas flexionais variam com relação à dimensão dessa redução - de maneira que esse é um dos parâmetros fundamentais de nossa tipologia. Seguindo Gomez-Imbert (2007), analisamos um sistema gradativo, que vai de uma categorização mais específica dos referentes nominais no domínio da palavra, para categorizações mais genéricas no $\mathrm{SN}$ e nos verbos:

Figura 2: Parâmetros morfossintáticos da categorização de referentes nominais

+Específico

-Específico

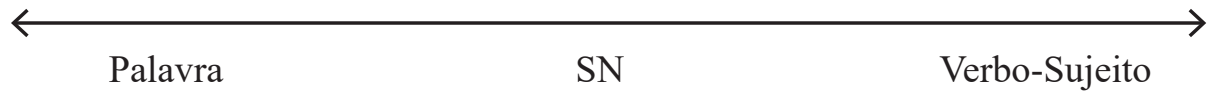

Esse fenômeno aponta que os verbos são o domínio de categorização dos referentes nominais mais sintéticos em termos de traços semânticos do que o sintagma nominal. Assim, por exemplo, a indexação verbo-sujeito é insensível aos traços plural e singular para referentes inanimados, e às subcategorizações operadas por classificadores. Dessa maneira, podemos resumir as categorias de classificação nominal presentes nos sistemas de indexação verbo-sujeito da seguinte forma:

(5) ANIMACIDADE > NÚMERO(ANIMADO) > GÊNERO (ANIMADO) > HUMANIDADE (ANIMADO)

A hierarquia acima indica que é mais provável no conjunto das línguas tukáno que a categorização dos referentes nominais dos sujeitos verbais se dê pelas categorias à esquerda da hierarquia do que à direita (cf. seções 3 e 4).

\section{Pessoa}

No nível do $\mathrm{SN}$, a categoria de pessoa é unicamente por pronomes. A maioria das línguas Tukáno, com exceção de Retuarã, apresenta um sistema de pronomes pessoais somente para referentes nominais animado, abrangendo as categorias ilustradas abaixo com dados da língua Kubeo:

Tabela 1: Pronomes língua Kubeo

\begin{tabular}{|c|c|c|}
\hline & SINGULAR & PLURAL \\
\hline 1 & yi & $\begin{array}{ll}\text { maha } & \text { (inclusivo) } \\
\text { yihã / ñihã } & \text { (exclusivo) }\end{array}$ \\
\hline 2 & $\mathrm{mi}$ & mihã \\
\hline 3 & $\begin{array}{l}\tilde{\tilde{\mathrm{f}}}[\text {-feminino }] \\
\tilde{\mathrm{o}}[\text { +feminino }]\end{array}$ & na \\
\hline
\end{tabular}


Gênero é somente relevante para as formas de $3^{\text {a }}$ pessoa animada singular. Número é marcado para todas as pessoas (ver discussão na seção sobre número abaixo): para $1^{\mathrm{a}}$ e $2^{\mathrm{a}}$, Kubeo evidencia uma formação diacrônica em que as formas para $1^{\text {a }}$ e $2^{\text {a }}$ pessoa singular foram sufixadas pelo morfema $h \tilde{a}$ 'associativo', com exceção da forma supletiva maha ' 1 a pessoal plural inclusiva', cujo étimo parece ser derivado da forma * $p$ 'ãi 'gente' do ProtoTukano e *tsã 'associativo'. A forma para $3{ }^{\text {a }}$ pessoa é derivada de $d i$ 'anafórico' $+-\tilde{a}$ 'plural'. Em Tuyuka (Barnes e Malone 2000) a forma para $3^{\text {a }}$ pessoa plural é $k \tilde{a} a$ historicamente derivada de $k \tilde{t}$ ' $3^{\mathrm{a}}$ pessoa singular não-feminino' e- $\tilde{a}^{\text {' }}$ plural animado'. As línguas TOc possuem formas mais complexas para os pronomes de terceira pessoa, diferenciando diversos pontos de referência dêitica (cf. Cook e Criswell 1993, Wheeler 1987).

Para a maioria das língua, nomes inanimados não possuem pronomes pessoais, e sua correferência anafórica/catafórica no discurso é feita por demonstrativos, classificadores e por pronomes anafóricos/catafóricos. $\mathrm{Ou}$ seja, pessoa não é uma categoria que se estende aos nomes inanimados nas línguas Tukáno ${ }^{7}$. $\mathrm{Na}$ análise dos indexadores verbo-sujeito vamos tratar sujeitos inanimados como sendo sempre equivalente a $3^{\text {a }}$ pessoa.

A língua Retuarã é um caso diferente, pois há uma forma pronominal para a classe "neutra" - que inclui animados não-humanos e inanimados (Strom 1992). Esse agrupamento é único nas línguas Tukáno, e revela a dimensão mais gramaticalizada da categoria de humanidade entre as línguas da famíliå

\section{Número}

Número é uma categoria secundária à classificação nominal e pessoa. $\mathrm{Na}$ classificação nominal, notamos sua correlação com genericidade, ponto que retornamos com relação ao sistema de indexadores verbo-sujeito na seção 4 . Com relação à pessoa, apresentamos que no sistema pronominal cada categoria de pessoa possui formas no singular e plural'.

\footnotetext{
${ }^{7}$ A título de discussão, vejamos que para línguas como o Português e o Inglês, os pronomes pessoais de terceira pessoa podem se referir a nomes inanimados.

${ }^{8}$ É plausível crer que essa excepcionalidade tem a ver com uma influência do sistema de classificação das línguas Arúak (Strom 1992). Retuarã e a língua próxima Tanimuka apresentam diversos elementos que sugerem mudanças causadas por contato com línguas Arúak (cf. Aikhenvald 2004).

${ }^{9}$ É conhecido o questionamento de que pronomes talvez não possam ser analisados como tendo "número", i.e. que a diferença entre eu e nós não é uma relação similar a garoto e garotos (Crobett 2004; Swirieska 2004). Mantemos a terminologia tradicional, no entanto, uma vez que ela é suficiente para os objetivos desse trabalho.
} 


\section{Tipologia da indexação verbo-sujeito em línguas Tukáno}

Sujeitos são argumentos com referentes nominais, de modo que a tipologia que propomos se baseia na comparação das categorias de pessoa, número e classificação nominal a partir de sua expressão nos nomes com as formas de expressão dessas categorias na indexação verbo-sujeito. Ou seja, a perspectiva funcional de nossa tipologia é o universo da categorização nominal Tukáno (seção 2), e nossas variáveis são as formas de expressão dessas categorias pelos paradigmas flexionais verbais. Assim, temos os seguintes parâmetros para a comparação das línguas Tukáno:

Tabela 2: Parâmetros tipológicos

\begin{tabular}{|l|l|}
\hline LOCUS DA INDEXAÇÃO & $\begin{array}{l}\text { prefixal / proclítico } \\
\text { sufixal / enclítico }\end{array}$ \\
\hline $\begin{array}{l}\text { ESTATUTO GRAMATICAL } \\
\text { (CF. SEÇÃO 1.1) }\end{array}$ & $\begin{array}{l}\text { argumento } \\
\text { correferência } \\
\text { concordância }\end{array}$ \\
\hline $\begin{array}{l}\text { CATEGORIAS DOS REFERENTES NOMINAIS } \\
\text { (CF. SEÇÃO2) }\end{array}$ & $\begin{array}{l}\text { Pessoa - 1, 2 e 3 } \\
\text { Número - singular e plural } \\
\text { Classificação nominal }\end{array}$ \\
\hline
\end{tabular}

Dividimos inicialmente os sistemas de indexação verbo-sujeito em 8 tipos, tomando como base a expressão marcada ou não-marcada de categorias que tornam cada paradigma singular com relação aos demais. Assim temos os seguintes tipos de paradigmas:

1. Impessoal (língua Koreguahe, seção 3.1)

2. $1^{\text {a }}$ pessoa (língua Wanano, seção 3.2)

3. $3^{\text {a }}$ pessoa singular (cópula afixal da língua Kubeo, seção 3.3)

4. $3^{\text {a }}$ pessoa com gênero (línguas TOc Siona, Sekoya e Maihïki, seção 3.4)

5. $3^{\mathrm{a}}$ pessoa com gênero e número (línguas TOr em geral, seção 3.5)

6. $3^{\mathrm{a}} \mathrm{com}$ prefixos pronominais (línguas TOr Tatuyo e Barasano, seção 3.6)

7. Indexação genérica de $2^{\mathrm{a}}$ pessoa (língua Kubeo, seção 3.7)

8. Indexação variável (língua Retuarã, seção 3.8)

Apresentemos os paradigmas de 1 a 8 conforme uma ordem relativa de crescente complexidade estrutural e semântica. 


\subsection{Koreguahe: paradigma impessoal}

Na língua Koreguahe (TOc), existem três morfemas de correferência verbo-sujeito no modo declarativo, conforme representado abaixo (Cook e Criswell 1993:55)

Tabela 3: Paradigma de correferência verbo-sujeito Koreguahe

\begin{tabular}{|l|l|}
\hline$-m o$ & ANIMADO SINGULAR FEMININO \\
\hline$-m e$ & ANIMADO PLURAL \\
\hline$-m i$ & $\begin{array}{l}\text { GENÉRICO: } \\
\text { ANIMADO SINGULAR NÃO-FEMININO; } \\
\text { INANIMADO }\end{array}$ \\
\hline
\end{tabular}

O sufixo -mo correferencia sujeitos animados singular feminino, independentemente da pessoa:

(6a) sai-maว-mo

ir-NEG-FEM

‘não vou/não vá' (ibid. 1993:55)

(6b) ãni-piวni-kua-mo yiวi

comer-terminar-perto-FEM eu

'acabei de comer' (ibid. 1993:67 [com adaptações])

O sufixo - me correferencia sujeitos animados plurais, independentemente da pessoa do discurso:

(7) koวi-piวra-si-na-ว-me yik ${ }^{\text {hina }}$

voltar-começar-PER-SUS.PL-VBLZ-PL nós(exclusivo)

'nós começamos a voltar' (ibid. 1993:67 [com adaptações])

(8) saa-ñu yii-me i-na

levar-DES.PL dizer-AN.PL este-PL

'Estes querem leva-lo' (ibid. 1993:83)

O sufixo - $m i$ correferencia os demais tipos de sujeitos, i.e. animados masculino singular e inanimados, independentemente da pessoa do discurso:

(9) Puerto Diego-na k kãi-ha-ว-mi yiวi

Puerto Diego-META dormir-POT-VBLZ-NÃO.FEMININO eu

'Dormirei em Puerto Diego' (ibid. 1993:65 [com adaptações])

(10) Ricardo mai-re naja ria $\mathrm{k}^{\mathrm{h}} \mathrm{k}^{\mathrm{h}} \mathrm{a}$ paa-mi

Ricardo nós-ESP mais muito força ter-NÃO.FEMININO

'Ricardo tem mais força do que nós' (ibid. 1993:82 [com adaptações]) 
(11) yia-ya kohวsa-sõ-mi

rio-CL crescer-INT-NÃO.FEMININO

'O rio subiu muito' (ibid. 1993:73 [com adaptações])

O mesmo sufixo é usado para orações com um argumento oblíquo:

(12) asu-mi yìi-re

calor-GENÉRICO eu-OBLÍQUO

'me faz calor'

Como vemos, neste sistema, PESSOA não é uma categoria relevante. NÚMERO é contrastivo somente para sujeitos animados. Dessa forma, analisamos que a forma genérica $-m i$ atualiza dois níveis de contraste na correferência verbosujeito:

1. ANIMADO $>$ INANIMADO

2. ANIMADO $>$ SINGULAR $>$ FEMININO $>$ NÃO-FEMININO

Ou seja, primeiramente - $m \dot{t}$ correferencia sujeitos inanimados. Em um segundo nível da hierarquia, ele correferencia todos os animados, singulares, não-femininos.

\subsection{Wanano: paradigma de $1^{\text {a }}$ pessoa}

Na língua Wanano, o modo declarativo com evidencial visual possui formas distintas de correferência verbo-sujeito para a $1^{\text {a }}$ pessoa animada do discurso, e formas genéricas para as demais categorias (Stenzel 2013:272).

Tabela 4 : Paradigma de correferência verbo-sujeito em Wanano

\begin{tabular}{|l|l|}
\hline$+\mathrm{i}$ & $1^{\text {a }}$ PESSOA PERFECTIVA \\
$-\mathrm{ha}$ & $1^{\text {a }}$ PESSOA IMPERFECTIVA \\
\hline & GENÉRICO: DEMAIS \\
$+\mathrm{re}$ & PERFECTIVA \\
$+\mathrm{ra}$ & IMPERFECTIVA \\
\hline
\end{tabular}

Os exemplos em (13) ilustram o uso de $-h a \mathrm{e}-i$ com $1^{\text {a }}$ pessoa singular $\mathrm{e}$ plural, respectivamente:

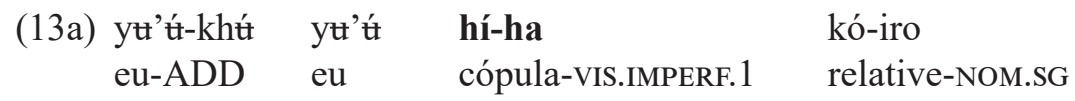

'Eu também sou teu parente' (ibid. 2013:275 com adaptações) 

(13b) to=wa'í-kíró $\quad \sim$ wahá+ri+ro-dita+re $\quad$ sá
$\mathrm{DEF}=$ animal $+\mathrm{SG}$ matar $+{ }_{\mathrm{NOM}}+\mathrm{SG}-\mathrm{apenas}+\mathrm{OBJ}$ nós(exc)
〜dá-thúá+í wut'ú -pú +ré
pegar-voltar+VIS.PERF. 1 house-LOC+OBJ
'Nós levamos para casa somente o animal abatido (pelo cachorro)' (ibid.
2013:275 com adaptações)

Os exemplos em (14) ilustram o uso de $+r a$ com sujeito inanimado e com terceira pessoa do discurso respectivamente:
(14a) a'rí tatía bi'sá 〜dítra
este quarto ser.apertado ser.PROG+VIS.IMPERF. $2 / 3$
'Esse quarto é apertado' (ibid. 2013:279 com adaptações)

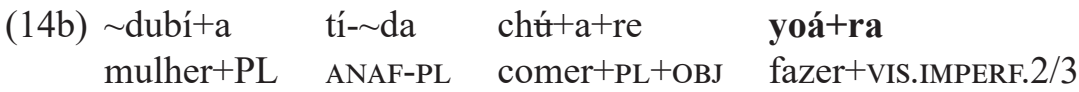

'As mulheres fazem sua comida' (ibid. 2013:281 com adaptações)

As formas genéricas do sistema Wanano atualizam dois níveis de contrastes na correferência verbo-sujeito:
1. ANIMADO
$>$
INANIMADO
2. ANIMADO
$1>\quad \mathbf{2}=\mathbf{3}$

Ou seja, primeiramente, +re e + ra marcam todos os sujeitos inanimados. Em segundo lugar, refletem uma cisão de pessoa nos sujeitos animados, marcando apenas $2^{\mathrm{a}}$ e $3^{\mathrm{a}}$ pessoa. Esse paradigma possui duas oposições, tal como o Koreguahe, porém GÊNERO não é uma categoria fundamental, mas, sim, PESSOA, diferentemente de Koreguahe. Animacidade é um categoria relevante indiretamente, pois pragmaticamente a distinção de pessoa para seres inanimados é de menor importância.

\subsection{Kubeo: cópula be/bu paradigma de $3^{\text {a }}$ pessoa singular}

Entre as várias cópulas da língua Kubeo, existe a cópula afixal be/bu que apresenta um contraste mais simples de correferência verbo-sujeito no modo declarativo:

Tabela 5: Paradigma da cópula be/bu em Kubeo

\begin{tabular}{|l|l|}
\hline -be / -me & $3^{\mathrm{A}}$ PESSOA ANIMADO SINGULAR \\
\hline -bu / -mu & GENÉRICO: \\
& ANIMADO PLURAL \\
& 1,2 PESSOAS \\
& INANIMADO \\
\hline
\end{tabular}


Os exemplos em (15) abaixo mostram como -be é indiferente à gênero:

(15a) o ira-ko-be

ela gorda-FEM-COP.3AN.SG

'ela é gorda'

(15b) $\tilde{\mathrm{t}} \quad$ ira-ki-be

ele grande-MSC-COP.3AN.SG

'ele é gordo'

Os exemplos em (16) mostram como - bu é usado para $3^{\text {a }}$ pessoa animada plural, para as demais pessoas do discurso e para sujeitos inanimados:

(16a) na põe-wa-mu

eles gente-AN.PL- COP. $1 / 2 / 3 \mathrm{IN} / 3 \mathrm{PL}$

'eles são gente'

(16b) yi pami-ki-bu

eu Kubeo-MSC-COP. $1 / 2 / 3$ IN/3PL

'Eu sou Kubeo'

(16c) yo ma hoa-rõ-mu

este caminho ser.longo-IN-COP. $1 / 2 / 3 \mathrm{IN} / 3 \mathrm{PL}$

'este caminho aqui é longo'

Como se vê, neste sistema, a forma genérica $-b u$ atualiza 3 níveis de contraste:

1. ANIMADO > INANIMADO

2. ANIMADO $>3>\mathbf{1}=\mathbf{2}$

3. ANIMADO $>3>$ SINGULAR $>$ PLURAL

$\mathrm{Ou}$ seja, primeiramente $-b u$ correferencia sujeitos inanimados. Num segundo nível, $1^{\text {a }}$ e $2^{\text {a }}$ pessoa versus a $3^{\text {a }}$ pessoa; e, então, correferencia todos os sujeitos animados plurais de terceira pessoa. Assim, apesar de ser um paradigma menor do que o sistema impessoal do Koreguahe (cf. seção 3.1), o indexador genérico concentra uma maior densidade funcional. Isso se dá devido à categoria de PESSOA, que cria uma subcategorização dos nomes animados, semelhantemente ao sistema Wanano. Porém, neste sistema Kubeo, PESSOA imediatamente domina a categoria de NÚMERO, criando assim um terceiro nível de contraste. No sistema Wanano, NúMERo não é uma categoria fundamental.

\subsection{TOc: paradigma de $3^{\mathrm{a}}$ pessoa com gênero}

Nas línguas TOc, com a exceção de Koreguahe, o modo declarativo possui formas específicas para $3^{\text {a }}$ pessoa animada singular feminina e não-feminina, 
conforme ilustrado abaixo com os dados do Siona para os verbos regulares (Wheeler 1987; Bruil 2013)

\section{Tabela 6: Paradigma modo declarativo presente Siona}

\begin{tabular}{|c|c|}
\hline -yi & $\begin{array}{l}1^{\mathrm{a}} \text { E } 2^{\mathrm{a}} \text { PESSOA } \\
3^{\mathrm{a}} \text { PESSOA PLURAL }\end{array}$ \\
\hline -ko & $\begin{array}{l}3^{\mathrm{a}} \text { PESSOA ANIMADA SINGULAR } \\
\text { FEMININA }\end{array}$ \\
\hline -hi & $\begin{array}{l}\text { GENÉRICO: } \\
3^{\text {a }} \text { PESSOA ANIMADA SINGULAR } \\
\text { MASCULINA } \\
\text { INANIMADO }\end{array}$ \\
\hline
\end{tabular}

Os exemplos em (17) ilustram os usos dos sufixos de correferência verbosujeito para todas as pessoas do discurso com sujeitos animados no tempo presente (cf. Wheeler 1987:152 com adaptações)

(17a) s'ia-ya-na gahe-hi

rio-CL.RIO-LD baixar.Se-PRES.3SG.NÃO.FEMININO

'Ele está descendo o rio'

(17b) s'ia-ya-na gahe-ko

rio- CL.RIO-LD baixar.Se-PRES.3SG.FEMININO

'Ela está descendo o rio'

(17c) s'ia-ya-na gahe-yi

rio-CL-LD baixar.Se-PRES.GENÉRICO

'Estou/Estamos/Estás/Estais/Estão descendo o rio'

Orações sem sujeito na língua Siona são marcadas pelo sufixo - $h i$ que também marca ' 3 a pessoa animada singular não-feminino' (18a), sendo o mesmo sufixo usado para sujeitos inanimados (18b):

(18a) oko-hi

chover- PRES.3SG.NÃO.FEMININO'está chovendo'

(18b) yua

ão si'a-hi

já comida acabar-PRES.3SG.NÃO.FEMININO

'já se acaba a comida'

O sistema TOc (representado pelo Siona, mas também presente nas línguas Sekoya e Maihïki) é interessante na comparação das línguas Tukáno pois ele opera com dois indexadores genéricos: um - o indexador genérico 
"canônico" - agrupa sujeitos INANIMADO com $3^{\mathrm{A}}$ PESSOA ANIMADA SINGULAR NÃO-FEMININO (semelhante ao Koreguahe, porém com a categoria de pessoa), e o outro - o indexador genérico secundário - agrupa $1^{\mathrm{A}}$ E $2^{\mathrm{A}}$ PESSOA COM $3^{\mathrm{A}}$ PESSOA PLURAL (semelhante à cópula Kubeo, porém sem incluir os referentes inanimados). Assim para o indexador genérico "canônico" temos os seguintes níveis de contraste:

1. ANIMADO $>$ INANIMADO

2. ANIMADO $>3>$ SINGULAR $>$ FEMININO $>$ NÃO-FEMININO

Como se vê, o indexador genérico TOc não é muito diferente do indexador genérico da língua Koreguahe (seção 3.1). Os contrastes intermediários no nível "2" acima são atualizados pelo indexador genérico "secundário" da seguinte maneira:

1. ANIMADO $>3>\mathbf{1}=\mathbf{2}$

2. ANIMADO $>3>$ SINGULAR $>$ PLURAL

É interessante notar que os traços essencialmente marcados no sistema TOc são os resultantes da combinação entre ANIMADO, $3^{\mathrm{A}}$ PESSOA, FEMININO, SINGULAR. Os demais são os não-marcados, fato que suscita os indexadores genéricos. Esse é um padrão recorrente nos sistemas de indexação verbo-sujeito na família - de modo que apesar de haver dois indexadores genéricos, esse sistema não é de modo algum idiossincrático sob um ponto de vista comparativo (cf. seção 4).

\subsection{Sistema TOr-1: paradigma de $3^{\text {a }}$ pessoa com gênero e número}

A maior parte das línguas TOr - as que não possuem prefixos pessoais verbais - possuem um paradigma para o modo declarativo, com evidencialidade visual ou de primeira mão, em que há três formas específicas para a terceira pessoa: feminino, não-feminino e plural, conforme ilustrado abaixo:

Tabela 7: Paradigma modo declarativo presente/passado recente Kubeo

\begin{tabular}{|l|l|}
\hline -bi & $3^{\text {a }}$ PESSOA SINGULAR NÃO-FEMININO \\
\hline -biko & $3^{\text {a }}$ PESSOA SINGULAR FEMININO \\
\hline -ma & $3^{\text {a } \text { PESSOA SINGULAR PLURAL }}$ \\
\hline -wi & $\begin{array}{l}\text { GENÉRICO: } \\
\text { INANIMADO } \\
\end{array}$ \\
$1^{\text {a }}$ E $2^{\text {a }}$ PESSOA \\
\hline
\end{tabular}


Os exemplos em (1) na seção 1.1 ilustram o uso dos sufixos de $3^{\mathrm{a}}$ pessoa, enquanto os exemplos em (2a) e (3) ilustram o uso do indexador genérico.

$\mathrm{O}$ indexador genérico nesse paradigma produz dois níveis de contraste, sendo alheio a categorias de gênero e número:

1. ANIMADO $>$ INANIMADO

2. ANIMADO $>3>\mathbf{1}=\mathbf{2}$

As categorias de GÊNERO e NÚMERO são restritas à subcategorização da terceira pessoa. A $3^{\text {a }}$ pessoa animada no plural possui um sufixo próprio, de modo que figura como um traço marcado. O mesmo vale para o feminino. Por contraste o não-feminino seria a categoria não marcada, seguindo o que fora discutido na seção 2 .

\subsection{Sistema TOr-2: paradigma de $3^{\text {a }}$ com prefixos pronominais}

Fazem parte do sistema TOr-2 apenas as línguas Tatuyo e Barasano. Essas línguas possuem um sistema que acrescenta a prefixação de marcas pessoais de $1^{\text {a }}$ e $2^{\mathrm{a}}$ pessoa à indexação verbo-sujeito típico do sistema TOr-1 (3.5). A combinação entre prefixos e sufixos cria um sistema modificado com relação a TOr-1. A tabela abaixo traz as marcas verbais de indexação de sujeito para a língua Barasano no aspecto imperfectivo ("no complido", cf. Gomez-Imbert 1982, 2000:131 e 2004:70):

Tabela 8: Paradigma Imperfectivo Barasano

\begin{tabular}{|c|c|}
\hline Prefixo & Sufixo \\
\hline \multirow{4}{*}{$\begin{array}{l}\text { Tom Alto-Baixo } \\
\text { prefixo tonal genérico ( } 3^{\mathrm{a}} \text { pessoa } \\
\text { animada, sujeitos inanimados, e } \\
\text { verbos sem argumentos) }\end{array}$} & -mi 3a 'pessoa singular não-feminino' \\
\hline & -mo 3 ' 'pessoa singular feminino' \\
\hline & 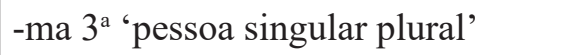 \\
\hline & -ha 'Inanimado' \\
\hline $\begin{array}{l}\text { Tom Alto } \\
\text { prefixo tonal para } 1^{\mathrm{a}} \text { e } 2^{\mathrm{a}} \text { pessoa }\end{array}$ & -ha ' 1 a e $2^{a}$ pessoa animada' \\
\hline
\end{tabular}

Em Barasano, os prefixos tonais não possuem material fonológico segmental, e sua presença pode ser atestada somente por sandhis tonais na raiz verbal. Paralelamente, todos os pronomes livres de $1^{\text {a }}$ e $2^{\text {a }}$ pessoa plural e singular possuem o mesmo tom alto. Em Tatuyo, em vez de prefixos tonais, tem-se a prefixação das formas pronominais - o que também ocasiona sandhis tonais na raiz verbal. Para a terceira pessoa e verbos sem argumentos (orações 
sem sujeito), não há prefixação de pronomes. Isso mostra um interessante paralelo morfofonológico em Tatuyo e Barasano. Para maiores detalhes sobre a complexa fonologia do sistema de correferência nessas língua ver GomezImbert (2004).

Gomez-Imbert (2000) analisa dois tipos de sufixo -ha (o qual interpretaríamos como o "indexador genérico"). O sufixo - ha que se combina com as formas prefixais de $1^{\text {a }}$ e $2^{\text {a }}$ pessoa indicaria apenas aspecto; enquanto o sufixo - ha que se combina com sujeitos de $3^{\text {a }}$ pessoa, indicaria aspecto e correferência verbo-sujeito. Essa interpretação reconhece uma homofonia pouco natural entre dois "tipos" de $-h a$. Isso ocorre porque ela interpreta que os prefixos pessoais de $1^{\mathrm{a}} \mathrm{e} 2^{\mathrm{a}}$ pessoa são os indexadores propriamente.

Nossa análise difere da de Gomez-Imbert (2000) em um ponto fundamental. Croft (2013) argumenta que pronomes livres e pronomes presos a verbos não são marcas de concordância propriamente, mas antes são morfemas com propriedades referenciais. Seguindo essa ideia, interpretamos que os prefixos pronominais (tonais como em Barasano ou segmentais como em Tatuyo) são a expressão de argumentos verbais propriamente, e não de marcas de correferência verbo-sujeito. A diferença do Tatuyo para o Barasano é que para o Barasano há dois pronomes genéricos não-segmentais: um de $3^{\mathrm{a}}$ pessoa e outro de $1^{\mathrm{a}}$ e $2^{\mathrm{a}}$ pessoa, enquanto em Tatuyo a $3^{\text {a }}$ pessoa não possui pronomes prefixais, somente a $1^{\mathrm{a}}$ e $2^{\mathrm{a}}$ - as quais são marcadas por formas diferentes para plural e singular. De fato, essa interpretação é mais problemática no caso Barasano, devido a que os pronomes são supra-segmentais. Torna-se necessário, portanto, interpretalos como um alomorfe suprassegmental, no contexto da palavra verbal, dos pronomes livres.

Nesse sentido podemos entender que a presença obrigatória de prefixos de pessoa que ocorre em Barasano e Tatuyo, concomitantemente à presença de sufixos de indexação verbo-sujeito, reflete a gramaticalização (i.e. a expressão obrigatória) do sujeito de $1^{\mathrm{a}} \mathrm{e} 2^{\mathrm{a}}$ pessoas (e $3^{\mathrm{a}}$ pessoa em Barasano). Dessa forma, o indexador genérico deve ser analisado como marca de concordância canônica (Corbett 2004). Isso nos faz pensar que essas línguas não são tão diferentes de línguas como o Inglês e o Alemão, em que o sujeito deve ser obrigatoriamente expresso por um nome ou pronome e o verbo correferenciado a eles por uma marca de concordância (cf. Haspelmath 2013:9).

Assim, o indexador genérico em Barasano e Tatuyo possui o mesmo estatuto que nas demais línguas TOr, isto é:
1. ANIMADO $>$ INANIMADO
2. ANIMADO $>3$
$>1=2$ 
A identificação de pessoa pode, assim, ser vista como redundante do ponto de vista do indexador genérico. Redundância é uma característica típica dos sistemas de "concordância canônica" (Corbett 2006:23), de modo que a presença de pronomes de $1^{\mathrm{a}} \mathrm{e} 2^{\mathrm{a}}$ pessoa em Barasano e Tatuyo torna o indexador genérico uma marca fundamentalmente de concordância. O que essa análise aponta é que no sistema TOr-2, os sufixos não apenas marcam correferência (como nas demais línguas Tukáno), mas sobretudo concordância quando os verbos possuem prefixos pronominais.

\subsection{Sistema Kubeo do passado remoto: indexador genérico de $2^{\mathrm{a}}$ pessoa}

O paradigma verbal mais complexo em termos de especificação semântica entre as línguas Tukáno é o do passado-remoto/estativos-genérico da língua $\mathrm{Kubeo}^{10}$. As formas desse paradigma são descritas a seguir

Tabela 9: Paradigma passado-remoto/estativo-genérico Kubeo

\begin{tabular}{|c|c|}
\hline -kaki & $1^{A}$ PESSOA SINGULAR NÃO-FEMININO \\
\hline -kako & $1^{\mathrm{A}}$ PESSOA SINGULAR FEMININO \\
\hline -karã & $1^{\mathrm{A}}$ PESSOA PLURAL EXCLUSIVO \\
\hline -ame & $3^{A}$ PESSOA SINGULAR NÃO-FEMININO \\
\hline -ako & $3^{\mathrm{A}}$ PESSOA SINGULAR FEMININO \\
\hline -ima & $3^{\mathrm{A}}$ PESSOA PLURAL \\
\hline -ãw̃̃ & $\begin{array}{l}\text { GENÉRICO: } \\
2^{\mathrm{A}} \text { PESSOA (SINGULAR E PLURAL) } \\
1^{\mathrm{A}} \text { PESSOA PLURAL INCLUSIVO } \\
\text { INANIMADO }\end{array}$ \\
\hline
\end{tabular}

O funcionamento desse paradigma é bem semelhante ao da tabela 7 (exemplificado nas orações em [1], [2] e [3]), porém há formas exclusivas para $3^{\text {a }}$ pessoa animada, e uma especificação única nos paradigmas analisados para a $1^{a}$ pessoa. $\mathrm{O}$ indexador genérico abarca um conjunto de categorias bem menos homogêneas à primeira vista. No entanto, podemos propor as seguintes generalizações:

\section{ANIMADO $>$ INANIMADO \\ 2. ANIMADO $>3>1=1+3^{11}>\mathbf{2}$}

\footnotetext{
${ }^{10}$ Quando combinados com temas verbais dinâmicos, essas formas codificam o passadoremoto, porém quando combinadas com temas estativos, elas codificam predicados estativos-genéricos (cf. Morse e Maxwell 1999; Chacon 2012).

${ }^{11}$ Seguindo generalização de Siewierska (2004), usamos o seguinte formalismo: 1 ( $1{ }^{\text {a }}$ pessoa
} 
Por esse paradigma ser mais específico semanticamente, a função do indexador genérico é relativamente a mesma dos paradigmas TOr-1 e TOr-2, ou seja: ele funciona para distinguir ANIMACIDADE e PESSOA. No entanto, essa é a única situação em que a $2^{a}$ pessoa se encontra em um estatuto de indexação distinto da $1^{\text {a }}$ ou da $3^{\mathrm{a}}$ pessoa, uma vez que sempre a $2^{\mathrm{a}}$ pessoa está indexada junto à $3^{\mathrm{a}}$ pessoa (cf. o sistema Wanano na seção 3.2 ) ou à $1^{\text {a }}$ pessoa (cf. os sistemas TOc, TOr-1 e TOr-2 nas seções 3.4, 3.5 e 3.6 respectivamente).

\subsection{Retuarã: indexação variável}

A língua Retuarã possui o sistema de indexação de sujeitos mais complexo sob um ponto de vista morfossintático e pragmático. Como as línguas geograficamente próximas Tatuyo e Barasano, o Retuarã possui um sistema de prefixação de marcas pessoais nos verbos e um sistema de sufixos. No entanto, em Retuarã os morfemas prefixais e sufixais não se combinam na mesma palavra verbal: ou o verbo traz prefixos ou sufixos (ver discussão abaixo relacionada ao exemplo [23b]). O paradigma das formas sufixais em Retuarã está representado abaixo (Strom 1992):

Tabela 10: Indexadores sufixais do Retuarã

\begin{tabular}{|c|c|}
\hline$-\mathrm{ki}$ & HUMANO SINGULAR MASCULINO \\
\hline$-\mathrm{ko}$ & HUMANO SINGULAR FEMININO \\
\hline -rã & ANIMADO PLURAL \\
\hline$-\mathrm{ka} / \mathrm{-a}$ & $\begin{array}{l}\text { GENÉRICO: } \\
\text { INANIMADO } \\
1^{\text {a }} \text { E } 2^{\text {a }} \text { PESSOA } \\
\text { ANIMADO não-humano } \\
\text { (3 } 3^{\text {a }} \text { PESSOA SINGULAR) }\end{array}$ \\
\hline
\end{tabular}

O sistema de indexadores sufixais em Retuarã apresenta uma variação entre uma indexação com base nos traços de PESSOA (como em TOr e TOc) ou com base puramente em traços de CLASSIFICAÇão NOMINAL (i.e. um sistema impessoal, como em Koreguahe). Isso pode ser ilustrado com as formas para a $1^{\text {a }}$ pessoa. Em (19a) e (19b) o sujeito yiวi 'eu' controla o traço de GÊNERO (feminino e masculino, respectivamente) com o verbo (Strom 1992:71):
(19a) õ-rĩ-be-yu-ko
yiวi
saber-EP-NEG-PRES-FEM eu
'Eu não sei'

singular); 2 (segunda pessoa singular); 3 ( $3^{\text {a }}$ pessoa singular); $1+2+3$ e $1+2$ ( $1^{\text {a }}$ pessoa plural inclusiva); $1+3$ (primeira pessoa plural exclusiva); $2+3$ (segunda pessoa plural); $3+3$ ( $3^{\text {a }}$ pessoa plural). 


\section{(19b) reya-be-sa-rã-ki yiวi \\ morrer-NEG-EP-FUT-MSC eu \\ 'não vou morrer'}

Já no exemplo (20), o mesmo sujeito de $1^{\text {a }}$ pessoa singular controla concordância com o sufixo $-k a$ 'indexador genérico', o que segue o padrão TOr-1:
(20) ãวã
yiวi-aka ã bĩti-ri-koวo-ka
$\operatorname{sim}$
eu-DIM Ouvir-EP-PST-GENÉRICO
'Sim, eu também ouvi'

Além desse tipo de variação, Retuarã apresenta um sistema de classificação nominal substancialmente diferente das demais línguas Tukáno, em que a categoria de HUMANIDADE possui um estatuto bem mais gramaticalizado, a ponto de agrupar referentes animados não-humanos com nomes inanimados. Assim, um animal como "cachorro" que tipicamente seria classificado como animado masculino nas demais línguas Tukáno, controla a concordância verbal com um indexador genérico em Retuarã (Strom 1992:218):
(21) yaiwẽko-a rĩ-yu-a
cachorro-NEUTRO correr-PRES-GENÉRICO
'O cachorro corre'

No entanto, no plural, sujeitos animados humanos e não-humanos são indexados pelo mesmo sufixo, o que mostra que essa é uma distinção que ocorre somente para sujeitos animados singulares.

Ocasionalmente, o indexador genérico também marca sujeitos animados humanos, como em (22) (Strom 1992:72)
(22) iəki baวa-koวo-ka
ele comer-PASSADO-GENÉRICO
'ele comeu'

Essa variação na indexação de sujeitos nos verbos é excepcional em Retuarã e parece estar ligada à mudanças nas estratégias de relações gramaticais na língua. Notemos, no entanto, que a escassez de dados não nos permite uma análise mais detalhada ${ }^{12}$.

Uma outra diferença fundamental é que em Retuarã os sufixos indexadores não são obrigatórios em duas circunstâncias: quando o sujeito é focalizado (como em [23a]), ou quando o verbo possui prefixos pronominais (como em

\footnotetext{
${ }^{12}$ Por exemplo, pode parecer suspeito que neste exemplo encontramos um pronome e não um nome livre.
} 
[23b]) (ibid. 1992:218-219):
(23a) toma-re ba?a-ko?o
Tomás-FOCO comer-PASSADO
'O Tomás comeu'
(23b) wa?ia ki-ba?a-ko?oc
peixe ele-comer-PASSADO
'ele comeu peixe'

As formas pronominais prefixais, que também marcam os possuidores, incluem todas as categorias de pessoa canônicas das línguas Tukáno (cf. seção 2), além de uma forma "neutra" $s a$ - com referentes inanimados e animados não-humanos. Pronomes livres, nomes ou sufixos indexadores não ocorrem na oração simultaneamente aos prefixos pronominais (Strom 1992:217) ${ }^{13}$.

Destaca-se ainda que o indexador genérico não é encontrado em construções sem sujeitos como discutido no exemplo (2) acima. Para predicados não-argumentais, como em (24), é obrigatória a presença do prefixo $s a$ - 'neutro' no verbo (Strom 1992:36):

\section{(24) hihia sa-baa-yu \\ frio 3.NEUTRO-fazer-PRES \\ 'faz frio'}

Notemos como a presença do nome hihia 'frio' em (24) simultaneamente a um prefixo pronominal parece contradizer a análise de Strom (1992:217) de que prefixos pronominais nunca ocorrem com nomes referentes a argumentos. Isso nos faz crer que hihia 'frio' não é um argumento, mas um nome em função oblíqua.

Como se vê nos exemplos acima, os indexadores sufixais podem ser interpretados como uma marca de concordância canônica (Corbett 2006) para argumentos pragmaticamente menos salientes (i.e. não focalizados), cuja presença enquanto um pronome livre ou nome é obrigatória na oração.

Já os prefixos pessoais, analisamo-os como argumentos, tomando-os como morfemas com propriedades referenciais. Quando são de terceira pessoa, esses prefixos podem realizar retomadas anafóricas, mas não são marcas de

\footnotetext{
${ }^{13}$ Os prefixos pronominais em Retuarã, assim como em Tatuyo, podem também ser usados como correferentes a objetos verbais, além de sujeitos. Assim, encontramos em Retuarã os seguintes tipos de estruturas: verbos transitivos com dois prefixos pronominais (OBJETOSUJEITO-VERBO); verbos com sufixos apenas para sujeitos, o objeto sendo expresso por um nome ou pronome livre (OBJETO SUJEITO-VERBO); e verbos com sufixos apenas para objetos, em que o sujeito é obrigatoriamente expresso na oração por um nome ou pronome livre (OBJETO-VERBO SUJEITO).
} 
concordância canônica, uma vez que não ocorrem na mesma oração onde há um nome ou um pronome livre referindo-se ao argumento (cf. Corbett 2006). No entanto, apesar de serem argumentos, esses pronomes cancelam o uso de sufixos indexadores. Isso nos mostra que eles possuem um estatuto ambíguo: são ao mesmo tempo argumentos e indexadores de pessoa, número e classificação nominal, de modo que uma subsequente indexação por sufixos se torna desnecessária. Isso indica que a função dos prefixos verbais do Retuarã é diferente dos prefixos verbais em Barasano e Tatuyo, onde prefixos verbais e sufixos indexadores co-ocorrem ${ }^{14}$.

O prefixo $s a$ - em construções como em (24) não é referencial, semelhante aos sujeitos expletivos de línguas como o Inglês e Francês. Isso nos mostra que em Retuarã a função de sujeito é um requerimento obrigatório em todas as orações (o mesmo vale para o Tatuyo e Barasano com relação a sujeitos de $1^{\text {a }} \mathrm{e}$ $2^{\mathrm{a}}$ pessoa).

Com base nisso, vemos que o indexador genérico em Retuarã não possui uma função bem definida. Mesmo assim, vamos tentar propor um sistema "canônico" à língua Retuarã, do qual a língua vem se desviando devido às variações do sistema criado pela indexação de pronomes prefixais em função de argumento e a questões de referencialidade. Assim, para este sistema canônico, teríamos a seguinte função do indexador genérico:

1. ANIMADO > INANIMADO

2. ANIMADO $>3>1=2$

3. ANIMADO $>3>$ SINGULAR $>$ NÃO-HUMANO

Ou seja, os sujeitos inanimados referenciados por nomes ou pronomes na oração são marcados pelo indexador genérico. Esse tipicamente indexa a $1^{\mathrm{a}} \mathrm{e}$ $2^{\text {a }}$ pessoa do discurso, tal como nos sistemas TOr-1 e TOr-2. Diferentemente de outros sistemas, o Retuarã cria uma distinção de humano e não-humano para os sujeitos animados singulares.

\section{Síntese dos tipos de indexação}

Nessa seção vamos fazer uma síntese das análises desenvolvidas nas seções anteriores e propor um conjunto de generalizações formalizadas em hierarquias semântico-gramaticais. Os parâmetros tipológicas propostas no início da seção 3 serão discutidas conjuntamente, de acordo com a natureza dos dados que indicam relações de implicações multilaterais entre elas. Começamos

\footnotetext{
${ }^{14}$ Para uma análise de indexadores pessoais como argumentos, pronomes anafóricos ou moremas de concordância ver Swirieska (2004) e Hapelmath (2013).
} 
discutindo Locus da indexação e estatuto dos indexadores e em seguida Categorização dos referentes nominais.

\subsection{Locus da indexação e estatuto dos indexadores}

Todas as línguas Tukáno possuem sufixos verbais que marcam a correferência verbo-sujeito. Os prefixos pronominais de $1^{\text {a }}$ e $2^{\text {a }}$ pessoa das línguas Tatuyo e o Barasano são analisados como argumentos obrigatórios, enquanto os sufixos que indexam $1^{\mathrm{a}}$ e $2^{\mathrm{a}}$ pessoa nessas línguas são analisados como marcas de concordância (seção 3.6). Na língua Retuarã, há sufixos de concordância verbo-sujeito (não obrigatórios), bem como prefixos pronominais (seção 3.8). Esses prefixos são morfemas suis generis pois obrigatoriamente dispensam a indexação verbo-sujeito por parte dos sufixos.

Locus de indexação (sufixo/enclítico e prefixo/proclítico) e estatuto gramatical dos indexadores (correferência, concordância e argumento) estão implicados. Isso justifica a seguinte hierarquia:

(25) SUFIXO-CORREFERÊNCIA > PREFIXO-ARGUMENTO > CONCORDÂNCIA

Se uma língua Tukáno tem somente sufixos indexadores, ela também terá apenas marcas de correferência verbo-sujeito. Se uma língua tem prefixos pronominais ela indexa diretamente à palavra verbal seus argumentos. Todas as línguas com prefixos verbais também possuem sufixos verbais como marcas de concordância canônica entre verbo-sujeito (mesmo que não ocorram simultaneamente na mesma oração como em Retuarã).

O que encontramos de variação entre as línguas é a obrigatoriedade da concordância, que não há para o Retuarã quando os argumentos são prefixais, mas somente quando eles são nomes ou pronomes livres não focalizados. De fato, quando há argumentos referenciados por nomes focalizados, Retuarã dispensa completamente o sistema de indexação verbo-sujeito, fato talvez explicado por uma economia icônica: quando o sujeito está pragmaticamente destacado, não se faz necessário o uso de indexação com o verbo nessa língua.

\subsection{Categorização dos referentes nominais}

O contraste entre sujeitos animados e inanimados é universal às línguas Tukáno. No entanto não existe uma indexação unicamente reservada às categorias animado ou inanimado. Sujeitos animados são sempre sub-categorizados por pessoa, número e/ou gênero. Sujeitos inanimados são marcados pelos indexadores genéricos, que sempre correspondem às categorias não marcadas das demais categorias de classificação nominal, pessoa e número. Isso pode ser representado pela seguinte hierarquia: 


\section{ANIMADO $>$ PESSOA - Número - Gênero}

Ou seja, subcategorizar sujeitos em termos de pessoa, número e/ou gênero implica em categoriza-los enquanto animados. A categoria de inanimado não possui subcategorizações na indexação verbo-sujeito - logo, ela é a categoria universalmente correferenciada pelo indexador genérico nas línguas Tukáno.

Número seria a categoria mais geral entre as demais categorias depois de animado e inanimado. Ele está ausente unicamente no paradigma de $1^{\mathrm{a}}$ pessoa do Wanano (assim como gênero, seção 3.2). Singular é a categoria marcada na cópula Kubeo (seção 3.3) e no sistema TOc (seção 3.4). Paradigmas que possuem uma forma para sujeitos animados plural também marcam explicitamente gênero como subcategorização do singular. Gênero é uma distinção privativa a sujeitos singulares, não havendo distinção de gênero para sujeitos plurais, o que está de acordo com a hierarquia universal de número (Corbett 2000). Isso suscita a seguinte generalização:

$$
\text { ANIMADO }>\text { SINGULAR }>\text { FEMININO }>\text { PLURAL }
$$

Ou seja, se uma língua marca explicitamente o plural, ela também marca sujeitos femininos singulares. Mas se uma língua marca explicitamente o feminino, isso não implica que ela marque explicitamente o plural (cf. o sistema TOc, seção 3.4). Já na cópula Kubeo, o singular é marcado, mas não há subcategorização por gênero. Gênero é, assim, secundário a número (Greenberg 1963:94) ${ }^{15}$.

Pessoa é uma categoria mais problemática. Primeiramente, notamos que os sistemas Koreguahe (3.1) e Retuarã (3.8) operam sem a noção de pessoa necessariamente. Em segundo lugar existe uma hierarquia interna às diferentes pessoas, como ilustrado a seguir ${ }^{16}$ :
a. 1 vs. $2=3$
b. 3 vs. $1=2$
c. 3 vs. $1=1+3 \quad$ vs. $2=1+2$

O indexador genérico é sempre reservado ao item não marcado nas hierarquias de pessoa acima. A hierarquia de pessoa em (a) é típica da língua Wanano ( $\left(1^{\mathrm{a}}\right.$ marcada versus $2^{\mathrm{a}}$ e $\left.3^{\mathrm{a}}\right)$; a em (b) é a mais generalizada na família

15 "Universal 32: "Whenever the verb agrees with a nominal subject or nominal object in gender, it also agrees in number". "Universal 36. If a language has the category of gender, it always has the category of number".

${ }^{16}$ É importante notar que o os sistemas de prefixos pronominais em Tatuyo e Barasano opera numa lógica inversa a (28b), i.e $1=2>3$. 
( $3^{\mathrm{a}}$ marcada versus $1^{\mathrm{a}}$ e $2^{\mathrm{a}}$ )( (seção $3.4,3.5$ e 3.6 ); e a em (c) é exclusiva do passado remoto Kubeo $\left(3^{\text {a }}\right.$ versus $1^{\text {a }}$ singular e $1^{\text {a }}$ plural exclusiva versus $2^{\mathrm{a}}$ pessoa e $1^{\text {a }}$ plural inclusiva).

Quando a língua destaca apenas $1^{\text {a }}$ pessoa (Wanano) não há subcategorização. Já a $2^{\text {a }}$ pessoa nunca é sub-categorizada nos paradigmas analisados, sendo sempre o elemento não marcado, correferenciada pelo indexador genérico. Quando uma língua destaca a $3^{\text {a }}$ pessoa, ela é sempre subcategorizada por gênero e/ou número. Gênero e número ocorrem nos sistema TOr (seção 3.5 e 3.6), passado remoto Kubeo (seção 3.7), enquanto apenas número, sem gênero, ocorre no sistema da cópula Kubeo (seção 3.5). O sistema TOc é mais problemático pois cria uma cisão da $3^{\mathrm{a}}$ pessoa com relação à categoria de número. Interpretamos isso como resultado de uma relação de redundância semântica, expressa pela hierarquia SINGULAR $>$ GÊNERO, i.e. gênero somente opera com referentes singulares. Assim, plural é uma categoria não-marcada no sistema TOc.

Como síntese a essa seção, apresentamos as seguintes hierarquias, em que combinamos pessoa, número e gênero:
A. ANIMADO $>1$
B. ANIMADO $>3>$ SINGULAR $>$ FEMININO $>$ PLURAL $^{17}$
C. ANIMADO $>3>1=1+3>$ SINGULAR $>$ FEMININO $>$ PLURAL

Notemos que a subcategorização dos referentes nominais em gênero e número é somente possível quando a $3^{\mathrm{a}}$ pessoa estiver em destaque na hierarquia de pessoa em (29), sendo a categorização de 1=1+3 decorrente de 3 ser de uma posição hierárquica superior.

Notemos também o paralelo entre categorização de gênero e número na indexação verbo-sujeito e o sistema pronominal das línguas Tukáno. A categorização de gênero em relação à $3^{\mathrm{a}}$ pessoa está de acordo com o sistema de pronomes livres das línguas Tukáno (seção 2) e também a tendências tipológicas universais ${ }^{18}$. A categorização de número restrita à $3^{\text {a }}$ pessoa é mais controversa tipologicamente; assim como é também controverso analisar a noção de número como uma flexão para os pronomes (cf. seção 2).

\footnotetext{
${ }^{17}$ Para incluir o sistema "canônico" da língua Retuarã na hierarquia em (30b), teríamos: ANIMADO $>3>$ SINGULAR $>$ HUMANO $>$ FEMININO $>$ PLURAL.

18 "Gender oppositions are characteristic of third rather than first or second person. Of the 133 languages in the sample (33\%) which have gender in their independent person forms, $129(97 \%)$ have gender in the third person as opposed to $24(18 \%)$ in the second and three in the first (3\%)" (Siewierska 2004:104).
} 


\subsection{Indexador genérico e suas motivações pragmático-funcionais}

O indexador genérico é um recurso formal nos paradigmas de indexação verbo-sujeito que agrupa um conjunto de categorias relativas a pessoa, número e classificação nominal. As hierarquias abaixo procuram dar conta de seu comportamento enquanto uma tendência tipológica às línguas Tukáno:

$\begin{array}{ll}\text { ANIMACIDADE: } & \text { INANIMADO }>\text { ANIMADO NÃO-HUMANO }>\text { HUMANO } \\ \text { NÚMERO: } & \text { PLURAL }>\text { SINGULAR } \\ \text { GÊNERO: } & \text { NÃO-FEMININO > FEMININO } \\ \text { PESSOA: } & 2>1>3\end{array}$

As hierarquias apontam para tendências de preferência do uso de indexadores genéricos pelas categorias situadas mais à esquerda. Da mesma forma, indicam que se algum item à direita for indexado pelo indexador genérico, os demais itens à esquerda também o serão.

O comportamento dos indexadores genéricos pode ser analisados como seguindo tendências funcionais-pragmáticas. Por um lado, eles possuem uma preferência por itens mais baixos na hierarquia de animacidade, com os inanimados e os animados não-humanos. Também possuem uma preferência pelo traço de plural em vez de singular. Isso sugere que plural e singular estão em analogia à oposição genérico e referencial. A associação entre individuação (singular) e referencialidade seria a motivação pragmática por trás de as línguas Tukáno tratarem o singular como marcado, o que implica que plural e genericidade estariam associados, e, assim, pragmaticamente menos proeminentes.

Por outro lado, a categoria de pessoa em (30) está em ordenamento diferente das tendências tipológicas universais. Tipologicamente, pessoa é comumente expressa pela hierarquia $1>2>3^{19}$. A $2^{\text {a }}$ pessoa é a mais baixa na hierarquia em (30) em decorrência do tipo de paradigma que estamos analisando neste trabalho, i.e. paradigmas de orações declarativas, com evidencialidade de primeira mão, modo realis (cf. seção 1). A $2^{\mathrm{a}}$ pessoa é em geral discursivamente mais proeminente no modo imperativo e interrogativo, enquanto no modo declarativo é normal que ela seja menos proeminente.

A $3^{\text {a }}$ pessoa figura mais regularmente como o elemento marcado nas línguas Tukáno, seguido de $1^{a}$ pessoa. Isso pode ser explicado pelo fato de que as línguas tendem a usar um recurso morfossintático mais complexo para indexar categorias menos salientes no discurso (Siewierska 2004:175, citando Ariel [1990]). A $3^{\text {a }}$ pessoa é pragmaticamente menos saliente do que a $1^{\text {a }}$, a que

\footnotetext{
${ }^{19}$ Isto é, qualquer categoria que se aplique à noção de pessoa é mais provável que se aplique antes à $1 \mathrm{a}$ do que à $2^{\mathrm{a}} \mathrm{e} / \mathrm{ou} 3^{\mathrm{a}}$ pessoa (Siewierska 2004).
} 
tem o domínio do discurso, o que faz com que a $3^{\text {a }}$ pessoa conte em geral com as formas marcadas de indexação nos paradigmas. Isso segue em linhas gerais o que Benveniste observou para a expressão linguística das pessoas do discurso (Benveniste 1976).

\section{Considerações finais}

A análise neste trabalho dos diferentes tipos de paradigmas de indexadores verbais baseou-se nos sistema de categorização dos referentes nominais de sujeitos a partir de categorias como classificação nominal (animacidade, humanidade, gênero), número (singular, plural e sua relação com referencialidade e genericidade) e pessoa. Propusemos uma hierarquia morfossintática de marcação das categorias nominais e notamos sua relação com as hierarquias semânticas e tipológicas universais. De especial relevância para os estudos morfológicos e semânticos é o tipo de morfema que aqui chamamos de indexador genérico, sempre associado aos traços não-marcados nos paradigmas em que analisamos.

Esse trabalho procurou abrir uma linha nova de investigação dos complexos paradigmas verbais nas línguas Tukáno. Estudos futuros deverão testar as generalizações aqui propostas, expandindo-as e refinando-as com a análise de novos paradigmas e categorias que aqui não foram abordados. Expandir o uso de certas noções e metodologias utilizadas nesse trabalho para línguas vizinhas às línguas Tukáno, bem como realizar um estudo diacrônico sobre a evolução dos sistemas de flexão verbal nas línguas Tukáno seriam os próximos passos para essa linha de investigação.

\section{Referências}

Aikhenvald, Alexandra Y. Classifiers. A typology of noun categorization devices. Oxford: Oxford University Press, 2000.

Ariel, Mira. 1990. Accessing Noun Phrase Antecedents. London: Croom Helm.

Barnes, Janet. 1984. Evidentials in the Tuyuca verb. IJAL 50.255-271.

Barnes, Janet \& Terrell Malone. 2000. El Tuyuca. In María Stella González de Pérez \& María Luisa Rodríguez Montes (eds.), Lenguas indígenas de Colombia: Una vision descriptive. 437-452. Santafé de Bogotá: Instituto Caro y Cuervo.

Benveniste, Emille. 1976. Estrutura das relações de pessoa no verbo (capítulo 18). Problemas e Linguística Geral, Isaac Nicolau Salum (org.). Série 5a-Letras e Linguística, v. 8. São Paulo: Editora da Universidade de São Paulo.

Bruil, Martine. 2014. Clause-typing and evidentiality in Ecuatorian Siona. LOT: Utrecht, the Netherlands. ISBN: 978-94-6093-133-8 
Chacon, Thiago Costa. 2014. A revised proposal of proto-tukanoan consonants and tukanoan family classification. $I J A L$, vol. 80 , no. 3, pp. 275-322.

. 2012. The phonology and morphology of Kubeo: The documentation, theory and description of an Amazonian language. Ph.D. dissertation, University of Hawai'i.

. 2007. O sistema de classificação nominal do Tukáno. Revista de Estudos e Pesquisa. IV. Brasília: Funai.

Corbett, Greville. 2000. Number. Cambridge: Cambridge University Press. . 2006. Agreement. Cambridge: Cambridge University Press.

Croft, W. 2013. Agreement as anaphora, anaphora as coreference. Languages across boundaries: studies in memory of Anna Siewierska, ed. Dik Bakker and Martin Haspelmath, 107-29. Berlin: De Gruyter Mouton.

Cook, Dorothy M. and Linda L. Criswell. 1993. El idioma koreguaje (tucano occidental). Bogotá: Asociación Instituto Lingüístico de Verano.

Gomez-Imbert, Elsa. 1982. De la forme et du sens dans la classification nominale en tatuyo (langue Tukano Orientale d'Amazonie Colombienne), Doctorat de 3e cycle. Paris: U. Paris-Sorbonne (=TDM 19, Editions ORSTOM, 1986), downloadable in www.ird.fr.

. 2007. Nominal classification in Tukanoan languages. In W. Leo Wetzels (ed.) Language Endangerment and Endangered Languages: Linguistic and Anthropological Studies with Special Emphasis on the Languages and Cultures of the Andean-Amazonian Border Area. Indigenous Languages of Latin America series (ILLA). Publications of the Research School of Asian, African and Amerindian Studies (CNWS). The Netherlands: Leiden University.

. 2004. Fonología de dos idiomas Tukano orientales. Amerindia. Vol. 29. Paris: CELIA.

. 2000. Como si tú y el agua fuesen una misma persona gramatical. Hein van der Voort \& Simon van de Kerke (eds.), Indigenous Languages of Lowland South America [Indigenous Languages of Latin America, 1], p. 129-148. Leiden: Research School of Asian, African, and Amerindian Studies (CNWS).

. 2011. La famille tukano. Dictionnaire des langues du monde, pp. 1454-60. Paris: Presses Universitaires de France.

Greenberg, Joseph. 1963 [1966]. Some Universals of Grammar with particular reference to the Order of Elements. Universals of language, ed. Joseph $\mathrm{H}$. Greenberg. 2nd edition. Cambridge, Massachusetts: MIT.

Grinevald, Colette. 2000. A morphosyntactic typology of classifiers, in: Gunter Senft (ed.), Systems of nominal classification. pp. 50-92. Cambridge: Cambridge University Press, 2000.

Grinevald, Colette \& Seifart, Frank. 2004. Noun Classes in African and Amazonian languages: Towards a comparison. Linguistic Typology 8.243-285. 
Haspelmath, M. 2013. Argument indexing: a conceptual framework for the syntax of bound person forms. In: Bakker, Dik \& Haspelmath, Martin (eds.) 2013. Languages across boundaries: Studies in memory of Anna Siewierska, 197-226. Berlin: De Gruyter Mouton.

Malone, Terrell. 1988. The origin and development of Tuyuca evidentials. IJAL 54/2: 119-140.

Mason, J. A. 1950. The languages of South American Indians. Bureau of American Ethnology Bulletin 143:157-317.

Miller, Marion. 1999. Desano grammar: Studies in the languages of Colombia 6. Summer Institute of Linguistics and the University of Texas at Arlington Publications in Linguistics, 132. Dallas: Summer Institute of Linguistics and the University of Texas at Arlington. xi.

Morse, Nancy L. \& Michael B. Maxwell. 1999a. Cubeo Grammar. (Studies in the Languages of Colombia, 5; SIL Publications in Linguistics, 130.) Arlington: SIL and University of Texas Arlington Press.

Ramirez, Henri. 1997. A fala Tukáno dos Ye’pa Masa: Gramática. Tomo I. 1 ed. Manaus: CEDEM.

Senft, Gunter (ed.). Systems of nominal classification. Cambridge: Cambridge University Press, 2000.

Siewierska, Anna. 2004. Person. Cambridge: CUP.

Silva, Wilson. 2012. A Reference grammar of Desano. PhD dissertation. University of Utah.

Skilton, Amalia. 2013. A new proposal of Western Tukanoan consonants and internal classification. Senior Thesis Essay. Yale University.

Stenzel, Kristine. 2013. A Reference Grammar of Kotiria (Wanano). Lincoln: University of Nebraska Press.

Strom, Clay. 1992. Retuarã Syntax: Studies in the Language of Colombia 3. Arlington: Summer Institute of Linguistics/University of Texas, 1992.

Wheeler, Alva. 1987. El pueblo siona del río Putumayo, Colombia. Vol. 1: Etnología, gramática, textos. Bogotá: Instituto Linguistico de Verano.

Data recebimento: 02/04/2014.

Data aceite: 18/04/2014. 